\title{
Accumulation of jitter in cascaded wavelength converters based on semiconductor optical amplifiers
}

\author{
Kloch, Allan; Stubkjær, Kristian
}

Published in:

Proceedings of Technical Digest Optical Fiber Communication Conference, 1999, and the International Conference on Integrated Optics and Optical Fiber Communication

Link to article, DOI:

10.1109/OFC.1999.765986

Publication date:

1999

Document Version

Publisher's PDF, also known as Version of record

Link back to DTU Orbit

Citation (APA):

Kloch, A., \& Stubkjær, K. (1999). Accumulation of jitter in cascaded wavelength converters based on semiconductor optical amplifiers. In Proceedings of Technical Digest Optical Fiber Communication Conference, 1999, and the International Conference on Integrated Optics and Optical Fiber Communication (Vol. 4, pp. 3335) https://doi.org/10.1109/OFC.1999.765986

\section{General rights}

Copyright and moral rights for the publications made accessible in the public portal are retained by the authors and/or other copyright owners and it is a condition of accessing publications that users recognise and abide by the legal requirements associated with these rights.

- Users may download and print one copy of any publication from the public portal for the purpose of private study or research.

- You may not further distribute the material or use it for any profit-making activity or commercial gain

- You may freely distribute the URL identifying the publication in the public portal 
FB4-1 / 33

\title{
Accumulation of jitter in cascaded wavelength converters based on semiconductor optical amplifiers
}

\author{
A. Kloch and K.E. Stubkjaer \\ Center for Broadband Telecommunications, Department of Electromagnetic Systems. \\ Technical University of Denmark, Building 348, DK-2800 Lyngby, Denmark. \\ Telephone: +4545881444 , telefax: +4545931634 \\ e-mail: ak@emi.dtu.dk
}

Introduction

Wavelength converters will be employed in future WDM networks to, e.g., reduce the wavelength blocking. The converters can, however, cause timing jitter that will accumulate in the network and thereby set an upper limit to the network size. Therefore, the accumulation of jitter through cascaded converters is important and is investigated here.

Focus is on the cascadability of converters based on cross-gain modulation (XGM) but the results are applicable to interferometric wavelength converters as both techniques are based on modulation of carriers in semiconductor optical amplifiers (SOAs) [1]. So far shortening of the SOA length has been identified as a way to minimize the jitter accumulation. This is, however, at the expense of a lower modulation bandwidth. We show that the jitter accumulation in a long SOA $(1500 \mu \mathrm{m})$ can be minimized by adjustment of the optical power levels. This enables alloptical wavelength converters to be cascaded at high bit rates.

\section{Network requirement}

Wavelength converters could be placed (i) at network interfaces for adaption between two different wavelength grids or (ii) in switch blocks enabling switching in the wavelength domain [2]. In both cases situations will occur, where the components must convert to the same wavelength. This can be accomplished by counter-propagating the signal and the $\mathrm{CW}$ light in an XGM converter as sketched in Fig. 1. However, this scheme constitutes a worst case for the jitter accumulation. In the following methods for minimizing the jitter accumulation are given.

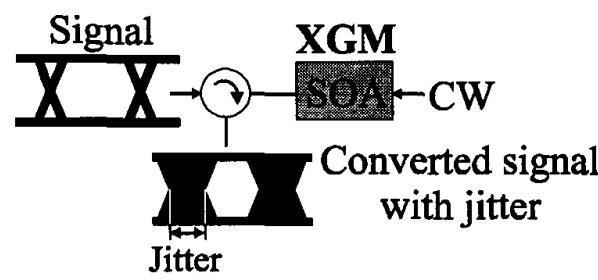

Fig. 1: Jitter arising from counterpropagation in an XGM converter.

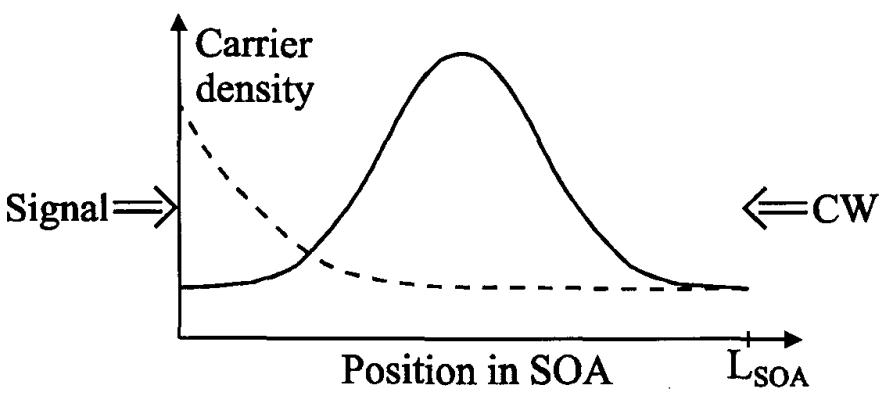

Fig. 2: Carrier density distributions in the XGMSOA for a fixed $C W$ power with an equal (-) and a higher (- - ) signal power level. 


\section{Jitter}

The jitter generated in the SOA based XGM converter is caused by the power dependent distribution of the carriers in the SOA. Fig. 2 shows two carrier distributions versus the position in the SOA, when the signal is introduced from the left and the CW light from the right. The solid curve is obtained when the signal and the $\mathrm{CW}$ power levels are equal causing a symmetric carrier distribution. The dashed curve shows the carrier density when the signal power is significantly higher than the $\mathrm{CW}$ power. In this case, the signal determines the carrier distribution because more carriers are depleted as the signal is amplified. Since the intensity of the incoming signal is modulated the carriers will redistribute for marks and spaces as shown in Fig. 2.

Due to the propagation time this movement of the gain in the longitudinal position of the SOA corresponds to a movement in time for the converted signal depending on the bit pattern. The result is that the converted signal will fluctuate resulting in an eye closure as shown in Fig. 1.

\section{Results}

The jitter accumulation is investigated with a model similar to the one described in [1]. Conversion to the same wavelength $(1555 \mathrm{~nm})$ of a pseudo random bit sequence is carried out in the XGM converter. After each cascaded component the power level of the converted signal is adjusted to maintain a fixed mean signal power level. A $1500 \mu \mathrm{m}$ long SOA biased with a current density of $\sim 25 \mathrm{kA} / \mathrm{cm}^{2}$ is examined. The initial extinction ratio of the $10 \mathrm{Gbit} / \mathrm{s}$ pulse train is 13 $\mathrm{dB}$.

In fig. 3 the extinction ratio versus the number of cascaded converters is shown for four different signal powers with a constant $\mathrm{CW}$ power of $-6 \mathrm{dBm}$. As seen the extinction ratio decreases for every conversion as expected for XGM conversion to the same wavelength [1]. It is also observed that the extinction ratio decreases the most for low signal powers, which is due to a weaker gain modulation. The extinction ratio for a high signal power of $6 \mathrm{dBm}$ remains very high $(>12 \mathrm{~dB})$ until the 18th converter after which the extinction ratio becomes unstable. The high extinction ratio together with the high signal power level causes a strong longitudinal movement of the SOA gain. The result is a severe eye closure due to jitter accumulation making it difficult to determine the extinction ratio.

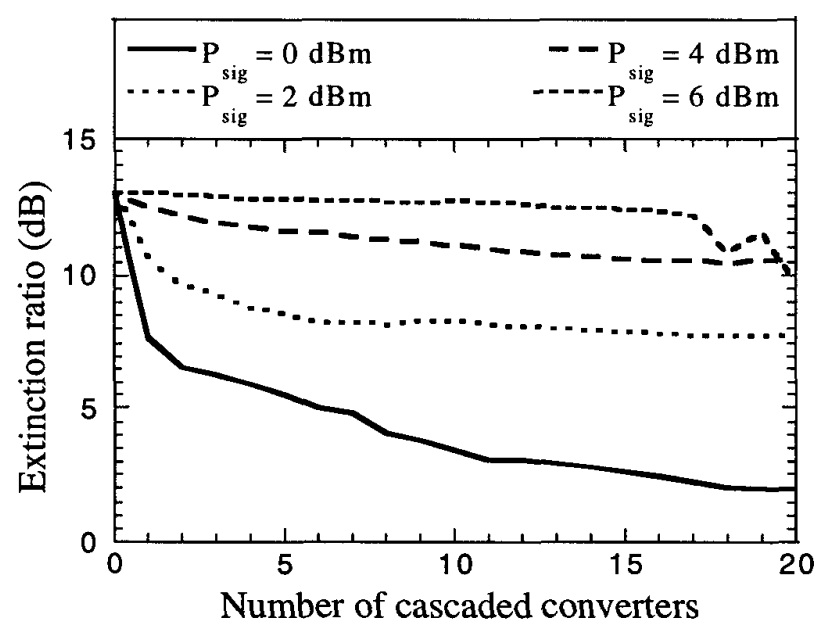

Fig. 3: The extinction ratio as a function of the number of cascaded converters. The CW power is -6 dBm while the signal power is a parameter. 
Clearly, a trade-off between a high extinction ratio and a small amount of accumulated jitter exists. In the following the jitter accumulation will be investigated thoroughly.

As the movement in the carrier distribution is determined by the ratio between the signal power and the CW power, Fig. 4 shows the jitter found after 10 and 20 converters as a function of this ratio. Curves for different $\mathrm{CW}$ power levels are shown all having a minimum at 9-10 dB. As seen, power optimization makes it possible after 20 converters to obtain as little as $\sim 20 \mathrm{ps}$ jitter corresponding to a fifth of the time slot. The extinction ratio for all of the values near the jitter minimum is higher than $9 \mathrm{~dB}$ after 20 converters. As an example, a signal power of $5 \mathrm{dBm}$ and a $\mathrm{CW}$ power of $-4 \mathrm{dBm}$ yields an extinction ratio of $9.6 \mathrm{~dB}$ and an accumulated jitter of only $17 \mathrm{ps}$ after 20 converters. Finally, it is noted that any drift in the signal power level can be counteracted by control of the $\mathrm{CW}$ power ensuring a small amount of jitter and a high extinction ratio.

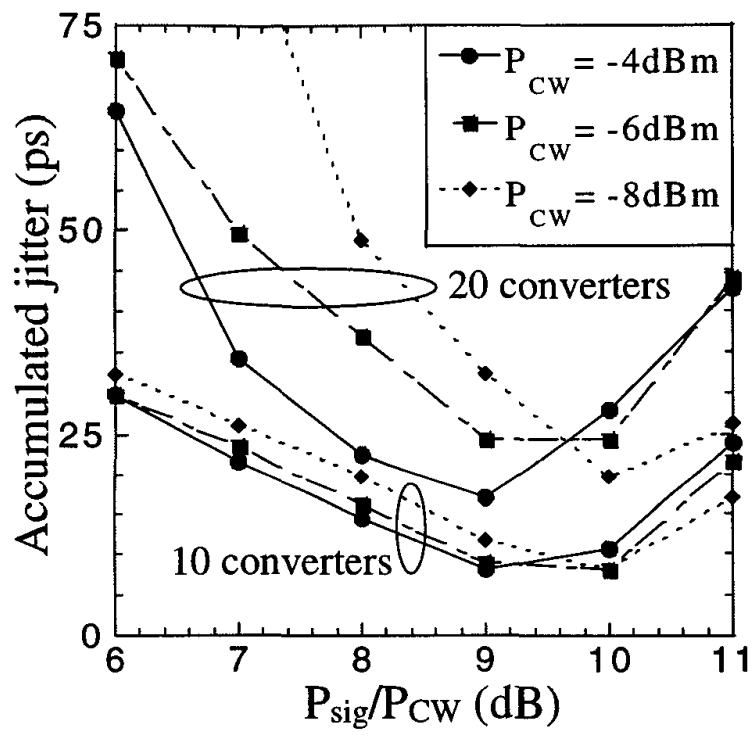

Fig. 4: The accumulated jitter for different $C W$ power levels as a function of the ratio between the signal and $C W$ power. Curves are shown both after 10 and 20 converters. The bit rate is $10 \mathrm{Gbit/s}$ corresponding to a time slot of $100 \mathrm{ps}$.

\section{Conclusion}

The jitter accumulation for conversion to the same wavelength using the counter-propagating XGM scheme was investigated. A trade-off between a high extinction ratio and a small amount of accumulated jitter was found predicting that the ratio between the $\mathrm{CW}$ and mean signal power levels should be $9-10 \mathrm{~dB}$. A cascade of 20 converters all converting to the same wavelength is predicted feasible with an extinction ratio of $9.6 \mathrm{~dB}$ and an accumulated jitter of only $17 \mathrm{ps}$. As the results found here are applicable to interferometric converters, we predict that large-scale high speed all-optical networks can employ wavelength converters without being limited by jitter accumulation from the converters.

\section{References}

[1] T. Durhuus et al., J. Lightwave Tech., vol. 14, pp. 942-954, June 1996

[2] M.W. Chbat et al., Proc. of ECOC'96, Paper WeP.11, pp. 3.253-3.256, Sept. 1996 